Article

\title{
Prebiotics for Lactose Intolerance: Variability in Galacto-Oligosaccharide Utilization by Intestinal Lactobacillus rhamnosus
}

\author{
Jason W. Arnold ${ }^{1}$, Joshua B. Simpson ${ }^{1}$, Jeffery Roach ${ }^{2}$, Jose M. Bruno-Barcena ${ }^{3}$ and \\ M. Andrea Azcarate-Peril 1,*(D) \\ 1 Center for Gastrointestinal Biology and Disease, Division of Gastroenterology and Hepatology, and UNC \\ Microbiome Core, Department of Medicine, School of Medicine, University of North Carolina, Chapel Hill, \\ NC 27599, USA; jason_arnold@med.unc.edu (J.W.A.); joshsimp@live.unc.edu (J.B.S.) \\ 2 Research Computing, University of North Carolina, Chapel Hill, NC 27599, USA; jeff_roach@unc.edu \\ 3 Department of Plant and Microbial Biology, North Carolina State University, Raleigh, NC 27607, USA; \\ jbbarcen@ncsu.edu \\ * Correspondence: azcarate@med.unc.edu, Tel.: +1-919-966-9838
}

Received: 27 September 2018; Accepted: 11 October 2018; Published: 16 October 2018

\begin{abstract}
Lactose intolerance, characterized by a decrease in host lactase expression, affects approximately $75 \%$ of the world population. Galacto-oligosaccharides (GOS) are prebiotics that have been shown to alleviate symptoms of lactose intolerance and to modulate the intestinal microbiota, promoting the growth of beneficial microorganisms. We hypothesized that mechanisms of GOS utilization by intestinal bacteria are variable, impacting efficacy and response, with differences occurring at the strain level. This study aimed to determine the mechanisms by which human-derived Lactobacillus rhamnosus strains metabolize GOS. Genomic comparisons between strains revealed differences in carbohydrate utilization components, including transporters, enzymes for degradation, and transcriptional regulation, despite a high overall sequence identity $(>95 \%)$ between strains. Physiological and transcriptomics analyses showed distinct differences in carbohydrate metabolism profiles and GOS utilization between strains. A putative operon responsible for GOS utilization was identified and characterized by genetic disruption of the 6-phospho- $\beta$-galactosidase, which had a critical role in GOS utilization. Our findings highlight the importance of strain-specific bacterial metabolism in the selection of probiotics and synbiotics to alleviate symptoms of gastrointestinal disorders including lactose intolerance.
\end{abstract}

Keywords: prebiotics for lactose intolerance; galacto-oligosaccharides; Lactobacillus; probiotics; $\beta$-galactosidases

\section{Introduction}

Lactose intolerance occurs as a result of decreased expression of intestinal lactase, and is often associated with lactose-induced abdominal pain, diarrhea, and intestinal distension [1]. Prebiotics are functional foods that stimulate the growth of gut native beneficial bacteria. Pure prebiotic galacto-oligosaccharides (GOS) have been shown to decrease symptoms of lactose intolerance [2-5]. GOS induced changes in the gut microbiota, increasing the abundance of lactose-fermenting Bifidobacterium, Faecalibacterium, Lactobacillus, and Roseburia species [3]. Changes to microbial diversity and microbiota composition suggest that members of the gut microbiota can revert lactose intolerance; however, the mechanisms by which GOS plays a role in this interaction have yet to be determined. Moreover, dietary GOS supplementation specifically promoted growth of bifidobacteria in humans, but this response was variable between individuals $[3,6]$. 
Commercially available GOS formulations are currently limited in their purity, with some having oligosaccharide contents as low as $48 \%$ weight/volume. Commercial formulations often contain some fraction of glucose $(0-22 \%)$, galactose $(0-39 \%)$, and lactose $(0-23 \%)$ [7]. The high concentration of lactose in the GOS preparation is of particular concern when the supplement will be administered to lactose-intolerant individuals. In clinical interventions aimed to determine the efficacy, safety, and tolerability of pure GOS in subjects with moderate to severe lactose intolerance $[3,8]$ the prebiotic was administered as a powder ( 5 to 7.5 grams twice daily). Likewise, the chemical formulation of prebiotics directly impacts microbial fermentation and growth at the strain level. For example, L. plantarum strain CLC17 is able to grow in a variety of GOS formulations including $4^{\prime}$-galactosyl-lactose, $6^{\prime}$-galactosyl-lactose, and pure lactose, while L. plantarum strain CLB7 is unable to utilize lactose or 4'-galactosyl-lactose [9], highlighting the importance of the prebiotic formulation in the microbial physiological response. Similarly, non-GOS components of dietary prebiotic formulations can impact the composition of the gut microbiota. Lactose promotes the growth of lactic acid bacteria [10], galactose can be utilized by Bacteroides [11], and dietary glucose is utilized by most bacteria, increasing the abundance of Proteobacteria and reducing Bacteroidetes when fed in high concentrations [12].

Bacterial members of the human gut microbiota provide a myriad of health benefits, including immunomodulation $[13,14]$, protection from pathogen colonization $[15,16]$, and unique metabolic capabilities $[17,18]$. The complex relationships between microorganisms and their host have profound impacts on overall health, with dysbioses often associated with gastrointestinal diseases. Thus, modulation of the gut microbiota is emerging as an effective method to prevent and treat gastrointestinal disorders $[19,20]$. Methods for microbiota modulation include treatment with probiotics, which add exogenous beneficial bacteria to the community [21,22], and prebiotics, which promote the growth of beneficial endogenous microorganisms [23].

Probiotics are live microbes, which when administered in adequate amounts provide a benefit to their host [24]. Members of the genus Lactobacillus are commonly used as probiotics. Species and strains of this genus have been shown to modulate host gene expression [25], prevent pathogen colonization [16,26,27], modulate the immune system [28], and improve the metabolic potential of host and community through fermentation of complex carbohydrates [29]. The impact that probiotics have on their host is directly related to their physiology, often highly variable between strains. In order for a microorganism to act as a probiotic, it must first survive the stresses associated with the gastrointestinal tract [30], a capability that is highly variable between strains [31-33]. Similarly, the mechanisms by which probiotics provide a benefit vary between strains, including carbohydrate fermentation [9], an important feature of probiotics [34].

Research studies have determined that the majority of the intestinal diversity is present at the species and strain levels $[33,35,36]$. In the gastrointestinal tract, GOS are metabolized by bacterial $\beta$-galactosidases and $\beta$-glucosidases, though mechanisms for GOS transport and utilization vary between species and strains [37]. In this study, we tested a high-purity formulation to yield results with a reduced or complete elimination of biases introduced by non-GOS components. Our study aimed to characterize the molecular mechanisms by which pure GOS are metabolized by L. rhamnosus [38]. We included strains AMC143 and AMC010, isolated from healthy human infants [38,39], LGG, a well characterized probiotic, isolated from a healthy human adult [40], and Lc705, derived from dairy products [41]. These strains exhibited physiological differences [33] despite sharing nearly $97 \%$ nucleotide identity between strains [38]. We hypothesized that the origin of the strains would impact their ability to metabolize prebiotics. Therefore, strain variability could directly impact efficacy of prebiotics when utilized to prevent or treat symptoms of lactose intolerance. 


\section{Materials and Methods}

\subsection{Bacterial Strains, Culture Media, and Cultivation}

L. rhamnosus strains used in this study are listed in Table 1. Strains were routinely propagated in MRS broth (Pronadisa, Madrid, Spain) at $37^{\circ} \mathrm{C}$ without agitation, or on MRS agar plates containing $1.5 \%$ agar. For growth assays, MRS without dextrose (Pronadisa, Madrid, Spain) was supplemented with either $1 \%$ glucose, $1 \%$ lactose, $1 \%$ GOS, $1 \%$ cellobiose, or $0.1 \%$ lactose. The high-purity prebiotics used in the study were composed of GOS (90\%) and lactose $(10 \%)[42,43]$. Since the GOS formulation contains $10 \%$ lactose, we used this disaccharide at $0.1 \%$ concentration as control for experiments using $1 \%$ GOS as the experimental condition.

Table 1. Bacterial strains used in this study.

\begin{tabular}{ccc}
\hline Strain & Origin & Reference \\
\hline L. rhamnosus GG & Healthy human isolate & {$[41]$} \\
L. rhamnosus Lc705 & Fermented dairy product & {$[41]$} \\
L. rhamnosus AMC010 & Human infant stool & {$[38]$} \\
L. rhamnosus AMC143 & Human infant stool & {$[38]$} \\
L. rhamnosus AMC143::P-_Bgal_lac3 & This study & \\
\hline
\end{tabular}

For growth assays, L. rhamnosus strains were cultured statically for $16 \mathrm{~h}$ in MRS broth at $37^{\circ} \mathrm{C}$. Freshly harvested cells were washed with MRS without dextrose and diluted 1:100 in MRS without dextrose supplemented with experimental carbohydrate sources. A total of $200 \mu \mathrm{L}$ of bacterial suspensions were transferred to 96 well plates, sealed, and placed into a Tecan Infinite 200 Pro spectrophotometer (Tecan, Mendendorf, Switzerland). Measurements of optical density at $600 \mathrm{~nm}\left(\mathrm{OD}_{600 \mathrm{~nm}}\right)$ were taken every $15 \mathrm{~min}$ during $24 \mathrm{~h}$. Growth curves were plotted in Origin2016 (OriginLab, Northampton, MA, USA), and maximum specific growth rates $\left(\mu_{\max }\right)$ were calculated for each treatment. Each experiment was performed with eight biological replicates and three technical replicates.

\subsection{Carbohydrate Fermentation Assays}

L. rhamnosus strains were grown overnight in MRS growth media at $37^{\circ} \mathrm{C}$ without agitation in duplicate. A total of $100 \mu \mathrm{L}$ of cultures were harvested via centrifugation, and cells were washed twice with API ${ }^{\circledR} 50 \mathrm{CHL}$ assay medium (BioMérieux, Marcy-Star, France). Washed cells were re-suspended in $10 \mathrm{~mL}$ of $\mathrm{API}^{\circledR} 50 \mathrm{CHL}$ assay medium. Cell suspensions were then transferred to $\mathrm{API}^{\circledR} 50 \mathrm{CH}$ and incubated at $37^{\circ} \mathrm{C}$ for $48 \mathrm{~h}$, as outlined by the manufacturer's instructions. Carbohydrate fermentation was determined for each sample at $24 \mathrm{~h}$ and $48 \mathrm{~h}$.

\subsection{Determination of GOS Metabolites}

L. rhamnosus strains were grown in minimal media $\left(10 \mathrm{~g}\right.$ yeast extract, $0.5 \mathrm{~g}\left(\mathrm{NH}_{4}\right)_{2} \mathrm{HPO}_{4}, 0.05 \mathrm{~g}$ $\mathrm{MnSO}_{4}, 0.005 \mathrm{~g} \mathrm{MgSO}_{4} \cdot 7 \mathrm{H}_{2} \mathrm{O}$ in $1 \mathrm{~L} \mathrm{H}_{2} \mathrm{O}$ ) supplemented with either $1 \%$ glucose or $1 \%$ GOS without agitation for $24 \mathrm{~h}$ at $37^{\circ} \mathrm{C}$. Samples were collected at early log growth phase $\left(\mathrm{OD}_{600 \mathrm{~nm}}=\sim 0.3\right)$, late log growth phase $\left(\mathrm{OD}_{600 \mathrm{~nm}}=\sim 0.7\right)$ and stationary phase and centrifuged to separate bacteria from media. The supernatants were filtered through $0.2 \mu \mathrm{M}$ filter, flash frozen, and stored at $-80{ }^{\circ} \mathrm{C}$ prior to High-Performance Liquid Chromatography (HPLC) analysis.

Products and substrates from each reaction were analyzed by HPLC (Shimadzu Corporation, Kyoto, Japan) under isocratic conditions at $65^{\circ} \mathrm{C}$ and at a $0.5-\mathrm{mL} \cdot \mathrm{min}^{-1}$ flow rate. The mobile phase was water using a Supelcogel Ca (300 mm by $7.8 \mathrm{~mm}$, Supelco Analytical, Bellefonte, PA, USA) coupled to a refractive-index and ELSD detectors. The column was calibrated using the GOS species pentasaccharide, tetrasaccharide (purified in house), galactosyl lactose (Carbosynth, Berkshire, UK), 
and lactose. Absolute values of glucose and galactose (Sigma-Aldrich, St. Louis, MO, USA) were also obtained by measuring known quantities to generate a standard curve.

\subsection{RNA Isolation}

Three biological replicates of strains AMC010, AMC143 and Lc705 were grown to late log phase in MRS containing $1 \%$ glucose $\left(\mathrm{OD}_{600 \mathrm{~nm}}=\sim 0.7\right), 1 \%$ GOS $\left(\mathrm{OD}_{600 \mathrm{~nm}}=\sim 0.3\right)$, or $0.1 \%$ lactose (vehicle control, harvested at the same time as GOS-treated samples) prior to harvesting. After reaching late log growth phase, cells were harvested via centrifugation, flash frozen in RNAlater (Thermo Fisher Scientific, Waltham, MA, USA), and stored at $-80^{\circ} \mathrm{C}$. RNA isolation was performed using the Qiagen RNeasy PowerMicrobiome kit (Qiagen, Valencia, CA, USA) following the manufacturer's instructions. RNA was eluted in $50 \mu \mathrm{L}$ RNase free water and quantified using the 2200TapeStation (Agilent Technologies, Santa Clara, CA, USA).

\section{5. $m R N A$ Sequencing}

Depletion of Ribosomal RNA was carried out using the Ribo-Zero Gold Bacterial rRNA Removal Reagent (Epidemiology Kit) (Illumina, San Diego, CA, USA) according to the manufacturer's instructions. Briefly, the rRNA-specific magnetic beads were removed from storage buffer and mixed with $500 \mathrm{ng}$ of total sample RNA. Subsequently, rRNA removal solution was added and samples were incubated for $10 \mathrm{~min}$ at $65^{\circ} \mathrm{C}$. Finally, samples were placed on a magnetic stand for $15 \mathrm{~min}$ at $22{ }^{\circ} \mathrm{C}$ and mRNA was removed and immediately processed with TruSeq Stranded mRNA HT kit (Illumina, San Diego, CA, USA). RNA was mixed with Fragment-Prime mix and incubated at $94{ }^{\circ} \mathrm{C}$ for $8 \mathrm{~min}$. Samples were immediately subject to first strand and second strand cDNA synthesis reactions, respectively, followed by $3^{\prime}$ end repair, adenylation and adapter ligation. After adapter ligation, the libraries were enriched by PCR using the following thermal cycling conditions: $98{ }^{\circ} \mathrm{C}$ for $30 \mathrm{~s}$ followed by 15 cycles of $98^{\circ} \mathrm{C}$ for $10 \mathrm{~s}, 60{ }^{\circ} \mathrm{C}$ for $30 \mathrm{~s}$ and $72{ }^{\circ} \mathrm{C}$ for $30 \mathrm{~s}$. A final extension step of $70{ }^{\circ} \mathrm{C}$ for $5 \mathrm{~m}$ was carried out following the last cycle. After enrichment, libraries were purified with magnetic beads (Beckman Coulter, Brea, CA, USA), washed with $80 \%$ ethanol and eluted in Tris $\mathrm{pH}$ 8.5. Following enrichment, cDNA was barcoded for multiplexing via PCR, using dual-index barcodes (index 1(i7) and index 2(i5)) (Illumina, San Diego, CA, USA) in a combination unique to each sample. Final ds cDNA was purified with magnetic beads. Library concentrations and quality were measured via TapeStation2200 (Agilent Technologies, Santa Clara, CA, USA). Barcoded libraries were pooled at equimolar concentrations and sequenced on the Illumina HiSeq platform (Illumina, San Diego, CA, USA).

\section{6. mRNA Sequencing Data Analysis}

Sequencing output from the Illumina HiSeq platform was converted to FASTQ format and demultiplexed using Illumina BclFastq 2.18.0.12 (Illumina, Santa Clara, CA, USA). Quality control was performed via FastQC on both raw and processed sequencing reads (Babrahm Institute, Cambridge, UK). Demultiplexed FASTQ sequence files were uploaded to Geneious software (Biomatters, Auckland, New Zealand). Sequencing reads from each treatment were mapped against Lc705 genome in Geneious software using "Geneious for RNA Seq" mapper, a minimum mapping quality of 30 (99.9\% confidence), allowing gaps with a maximum of $10 \%$ per read, $20 \%$ maximum mismatches per read, with word length of 20 bases. Expression levels were calculated in Geneious and compared between treatment types. Genes identified as significantly differentially regulated between treatments via Binomial Distribution analysis in Geneious software and post-analysis Bonferroni correction for multiple comparisons $(p \leq 0.05)$ were further filtered to include only genes with 2-fold expression differences. Genes identified as significantly differentially regulated at $\geq 2$-fold in at least one treatment type for each isolate were plotted as heat maps in OriginLab software (Origin Lab, Northampton, MA, USA), and compared between strains to show differences. 


\subsection{Generation of GOS Operon Insertion Mutant Strains}

Electrocompetent $L$. rhamnosus cells were generated using a combination of previously described methods [44,45], with minor adjustments [33]. Insertional inactivation of the 6-phospho- $\beta$-galactosidase gene in L. rhamnosus AMC143 was performed as previously described [33,44]. Briefly, primers GOS_p $\beta$ gal-F-EcoRI (5'-AATAGAATTCACAATTAGGCATTGCATTGCC-3') and GOS_p $\beta g a l-R-B a m H I$ (5'-TAATGGATCCTGAATCGAAGTGATGCAGCG-3') were designed to amplify a $440 \mathrm{bp}$ region of the GOS-specific 6-phospho- $\beta$-galactosidase gene in AMC143 ( $p$ - $\beta$ gal_lac3). These primers included EcoR1 or BamHI restriction sites for cloning into the pFAJ-5301 vector [13]. The resulting vector (pFAJ-pßGAL_lac3) was used to transform AMC143 by electroporation. Electrotransformed AMC143 cells were allowed to recover for $24 \mathrm{~h}$ in MRS at $37^{\circ} \mathrm{C}$ without agitation, and subsequently plated on MRS containing erythromycin at a final concentration of $2 \mu \mathrm{g} / \mathrm{mL}$. Individual erythromycin resistant colonies were selected after $48 \mathrm{~h}$ of growth at $37^{\circ} \mathrm{C}$ and sub-cultured in MRS containing $2 \mu \mathrm{g} / \mathrm{mL}$ erythromycin overnight without agitation at $37^{\circ} \mathrm{C}$. Insertion mutant AMC143::p p pgal_lac3 was verified by PCR amplification of the entire 6-phospho- $\beta$-galactosidase gene, using the primer set: V-p $\beta$ GAL-F (5'-ATGAGTATGAACGACTGGCG-3') and V-pßGAL-R (5'-TAATGCAAAAACAGACACGC-3'). Successful insertion mutants contained a $2 \mathrm{~kb}$ insertion in the target gene.

\section{Results}

\subsection{Comparative Genomic Analysis of GOS Utilization Genes}

In Bifidobacterium and Lactobacillus species, GOS and lactose are metabolized by $\beta$-galactosidases and $\beta$-glucosidases [46]. A comparison of strains in this study showed that the genome of L. rhamnosus AMC010 had the highest number of genes annotated as ' $\beta$-galactosidase' or 'phospho- $\beta$-galactosidase'. The genes were encoded in five different operons, each containing a different $\beta$-galactosidase gene (three different 6-phospho- $\beta$-galactosidases (EC 3.2.1.85), one $\beta$-galactosidase- 3 gene, and $\beta$-galactosidase large and small subunit (EC 3.2.1.23)) (Figure 1). Operon AMC010_lac1 had no homologs in the other three strains evaluated in this study with a nucleotide identity below $70 \%$ when compared to the shared genes in the lac2 operon of each of the other strains. This operon showed the highest identity with plasmids from L. paracasei and L. rhamnosus Lc705 ( $99 \%$ nucleotide identity). AMC010_lac1 shared a similar organizational structure with AMC010_lac2, but their identity was below $70 \%$. Homologs to each gene in the operon AMC010_lac2 were identified in all four strains with $98 \%$ or higher nucleotide identity. Operon AMC010_lac3 was present in AMC143 and Lc705 but absent in LGG, and had a different organization with a putative terminator identified between the phosphotransferase system (PTS) subunit IIB and the $b g l$ anti-terminator gene. AMC010_lac4 also contained a unique $\alpha$-galactosidase gene absent in the other strains in our study. All of the other genetic components had homologs in the analyzed strains. The AMC010_lac5 operon contained large and small subunits of the $\beta$-galactosidase, and was absent in the genomes of the other strains in this study. However, this $\beta$-galactosidase_lac 5 gene was $99.6 \%$ identical to a $\beta$-galactosidase gene identified in Lc705 plasmid FM179324.1 [41], and 99\% identical to a chromosomally encoded $\beta$-galactosidase in L. plantarum strain HFC8 [47], suggesting that this operon may be plasmid encoded in AMC010. Finally, AMC143 encoded a unique $\beta$-galactosidase gene absent from Lc705 and AMC010, but 99\% identical to other L. rhamnosus strains. Operons lac2, lac3, and lac4 were highly conserved in L. rhamnosus, but absent in other Lactobacillus species, with nucleotide identity below $30 \%$ in L. casei, a close relative to L. rhamnosus.

Analysis of potential transporters in the genome sequences of L. rhamnosus strains showed that AMC143 encoded the highest number of putative transporters of the phosphotransferase system (PTS) ( 99 genes), providing the strain with the capability to transport at least 16 different carbohydrate substrates based on our genome annotations (Table 2). Lc705 encoded 92 PTS genes, allowing for the transport of 17 unique carbohydrate substrates, the largest number among strains in this study. AMC010 encoded 92 PTS genes targeting 16 different substrates, and LGG encoded 78 transporters 
targeting 15 different substrates (Table 2). In addition to PTS transporters, L. rhamnosus strains encoded ATP-binding cassette (ABC) transport systems. These systems generally facilitate the transport of peptides and metals into the cell, but carbohydrate-specific ABC transporters including transporters for $N$-acetyl-D-glucosamine and maltose/maltodextrin were identified, and were highly conserved between strains, with nucleotide identities over $98 \%$. Few ABC transport genes have been characterized in L. rhamnosus. Genome analysis revealed that AMC010 encoded 127 putative ABC transport genes, AMC143 encoded 133 ABC transport genes, LGG encoded 196, and Lc705 encoded 215, many of which were uncharacterized, with unknown substrates. In L. acidophilus, the lacS permease is responsible for the internalization of GOS [37]. Our analysis revealed that this gene was absent in L. rhamnosus, suggesting a different mechanism for GOS uptake.

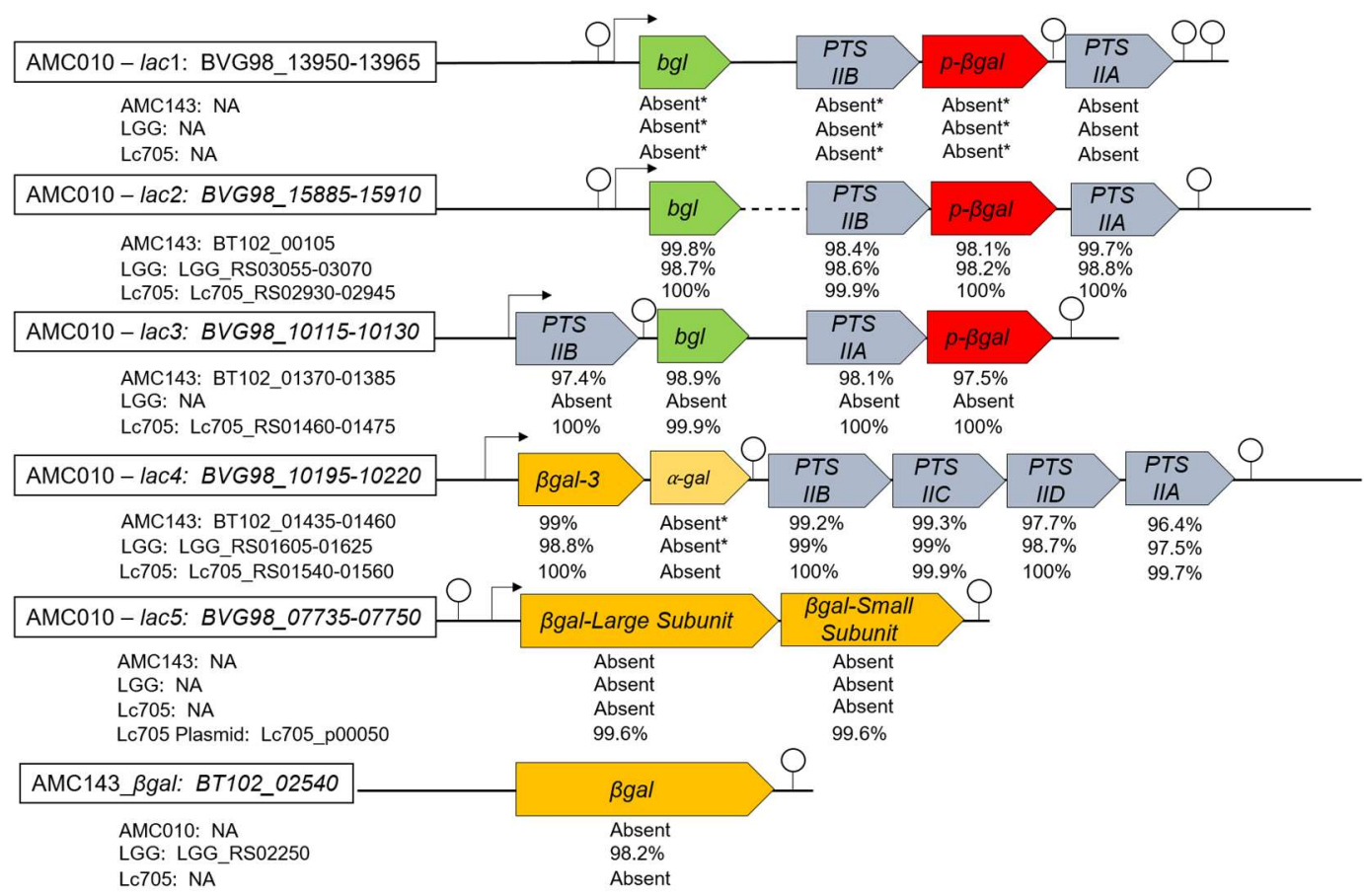

Figure 1. Comparative genomic of lactose metabolism operons in Lactobacillus rhamnosus. Genomes were analyzed using Geneious software, comparing operon organization and nucleotide identity between the human isolates AMC010, AMC143, LGG, and the dairy isolate Lc705. Promoters were identified using the BPROM (Softberry, Bangkok, Thailand) promoter prediction tool [48]. Terminators were identified using the ARNold terminator prediction tool [49]. * Genes showed $>60 \%$ identity to homologs in lac2 operon; bgl: beta glucoside antiterminator; PTS: phosphotransferase system; NA: not applicable.

Galactose is imported by the galactokinase galKETRM operon in L. casei strain 64H [50]. A homolog of this operon was identified in L. rhamnosus (designated as galKETRM), though only conserved with $60 \%$ nucleotide identity compared to L. casei $64 \mathrm{H}$. However, a second galactose metabolism operon (designated as galKETRMa in this study), distinctly different from L. casei galKETRM operon, was present in the four L. rhamnosus strains with $98.5 \%$ nucleotide identity between strains. Our genomic analysis regarding conserved and variable carbohydrate transport and metabolism systems suggested that variability in the ability of a microorganism to utilize carbohydrates occurs at the strain-level. 
Table 2. Quantification and qualification of annotated phosphotransferase system (PTS) transporters in L. rhamnosus strains. Open Reading Frames (ORF) numbers for each gene can be found in Table S2.

\begin{tabular}{|c|c|c|c|c|c|c|c|c|}
\hline \multirow[t]{2}{*}{ Strain } & \multicolumn{8}{|c|}{ Carbohydrate Transported } \\
\hline & $\alpha$-Glucoside & Ascorbate & $\beta$-Glucoside & Cellobiose & Fructose & Galactitol & Galactosamine & Galactose \\
\hline LC705 & 1 & 8 & 5 & 9 & 18 & 5 & 0 & 0 \\
\hline LGG & 0 & 5 & 3 & 10 & 12 & 9 & 0 & 0 \\
\hline AMC143 & 0 & 0 & 5 & 24 & 8 & 3 & 4 & 6 \\
\hline \multirow[t]{2}{*}{ AMC010 } & 0 & 0 & 4 & 14 & 10 & 5 & 4 & 6 \\
\hline & Glucitol & $\begin{array}{l}\text { Hyaluronate- } \\
\text { Oligosaccharide }\end{array}$ & Uncharacterized & Glucose & Lactose & Maltose & Mannitol & Mannose \\
\hline LC705 & 1 & 0 & 10 & 4 & 6 & 1 & 2 & 8 \\
\hline LGG & 1 & 0 & 7 & 3 & 6 & 0 & 2 & 13 \\
\hline AMC143 & 4 & 2 & 7 & 0 & 5 & 2 & 4 & 15 \\
\hline \multirow[t]{2}{*}{ AMC010 } & 4 & 2 & 3 & 0 & 8 & 4 & 4 & 13 \\
\hline & $\begin{array}{l}\text { Mannose/ } \\
\text { Fructose/ } \\
\text { Sorbose }\end{array}$ & $\begin{array}{c}N \text {-acetyl } \\
\text { galactosamine }\end{array}$ & $\begin{array}{c}N \text {-acetyl } \\
\text { glucosamine }\end{array}$ & Sorbitol & Sorbose & Trehalose & Sucrose & Total \\
\hline LC705 & 2 & 3 & 3 & 2 & 3 & 1 & 0 & 46 \\
\hline LGG & 1 & 0 & 0 & 2 & 2 & 1 & 1 & 39 \\
\hline AMC143 & 0 & 2 & 0 & 0 & 3 & 1 & 4 & 50 \\
\hline AMC010 & 0 & 2 & 0 & 0 & 3 & 2 & 4 & 43 \\
\hline
\end{tabular}

\subsection{Carbohydrate Utilization by L. rhamnosus}

The genomic differences identified between strains led us to assess their impact on phenotype. Carbohydrate fermentation profiles generated using the API CH50 system showed unique profiles for each strain (Supplemental Table S1). The probiotic strain LGG was unable to ferment lactose, while all other strains showed positive signals for lactose fermentation within $24 \mathrm{~h}$. Strains Lc705 and AMC143 were the most efficient at fermenting GOS, fully fermenting the substrate within $24 \mathrm{~h}$, while AMC010 only partially fermented GOS. LGG was also unable to ferment GOS at $24 \mathrm{~h}$; however, all strains exhibited at least partial utilization after $48 \mathrm{~h}$. The fermentation of other carbohydrates including gentiobiose, maltose, amygdalin, sorbitol, sorbose, rhamnose, and ribose, varied between strains, revealing unique carbohydrate fermentation profiles for each strain. L-fucose, a major component of intestinal mucus, was fermented by neither AMC010 nor Lc705, but was utilized by LGG and AMC143.

Culture experiments in a complex medium containing $1 \%$ glucose, $1 \%$ GOS or $0.1 \%$ lactose $(w / v)$ as a sole carbohydrate source showed that LGG had the highest maximum specific growth rate in glucose $\left(0.68 \mathrm{~h}^{-1}\right)$ but was unable to grow in GOS or lactose; consequently, it was omitted from subsequent expression experiments. Glucose was also the preferred substrate for AMC010, but the difference in specific growth rate between GOS and lactose was minimal $\left(0.19 \mathrm{~h}^{-1}\right.$ and $0.22 \mathrm{~h}^{-1}$, respectively). Lc705 was able to utilize both GOS and lactose, growing at approximately the same rate in each $\left(0.14 \mathrm{~h}^{-1}\right.$ and $0.11 \mathrm{~h}^{-1}$, respectively) (Figure 2). AMC143 exhibited the lowest specific growth rates in this study $\left(0.34 \mathrm{~h}^{-1}\right.$ in glucose and $0.08 \mathrm{~h}^{-1}$ in GOS and lactose) (Figure 2).

Analysis of GOS fermentation products showed that AMC010 fully metabolized lactose by the time it reached stationary phase $24 \mathrm{~h}$ post inoculation, while leaving the majority of GOS tri- and tetrasaccharides intact, confirming our previous observation that AMC010 utilized primarily the lactose component of the GOS formulation. Conversely, AMC143 simultaneously fermented lactose and the trisaccharide, only utilizing larger GOS oligomers when trisaccharide concentrations were reduced (Figure 3). Finally, Lc705 fully fermented the lactose in the medium by early log growth, and began the utilization of trisaccharides once lactose was no longer present. These sugar consumption patterns correlated with the generation of products, showing that both Lc705 and AMC143 generated over four times the amount of lactate $(5 \mathrm{~g} / \mathrm{L}$ and $4 \mathrm{~g} / \mathrm{L})$ than AMC010 $(1 \mathrm{~g} / \mathrm{L})$ when grown in GOS. 


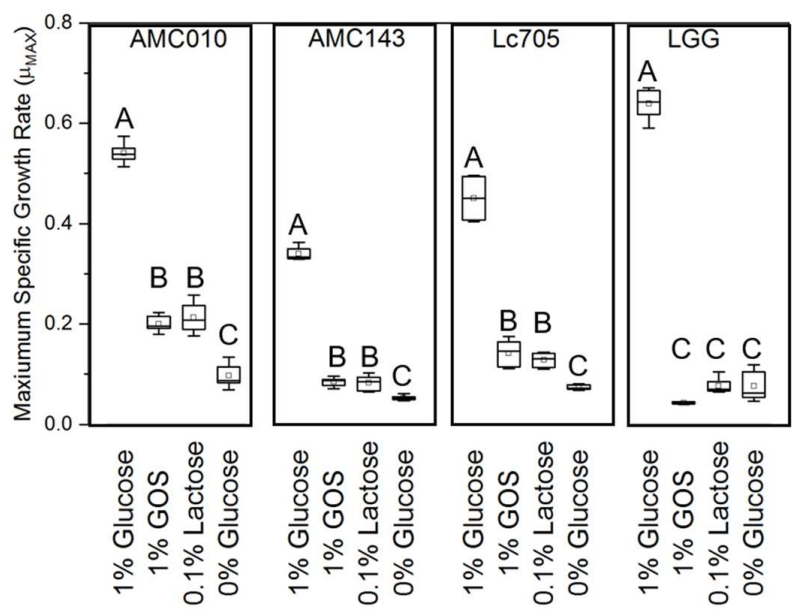

Figure 2. Specific growth rates of L. rhamnosus strains. Growth rates were calculated for each strain in MRS containing $1 \%$ glucose, $1 \%$ GOS, $0.1 \%$ lactose (the lactose component of GOS formulation), and in MRS without carbon and energy sources. Eight biological replicates, each in triplicate (three technical replications) were included in each experiment. Letters (A, B, C) represent statistical differences between treatments in each strain $(p<0.05)$.

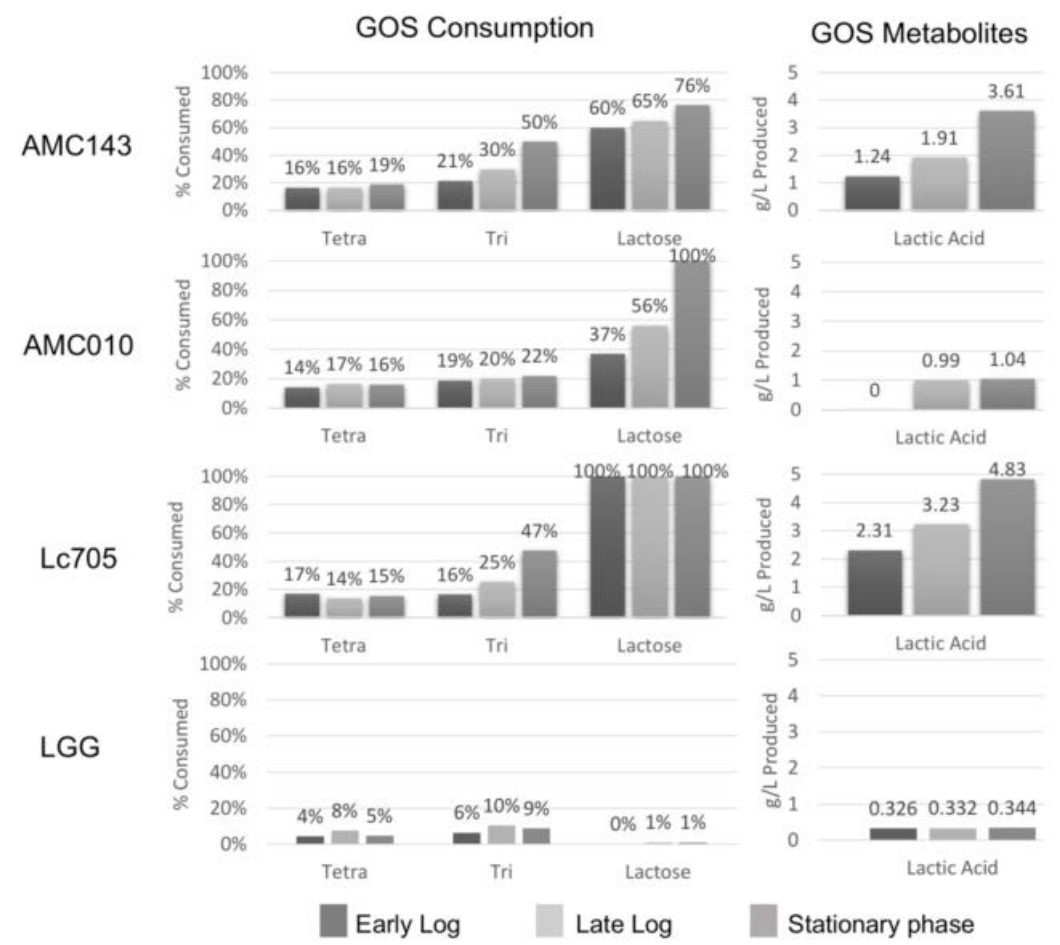

Figure 3. GOS utilization and generation of secondary metabolites. Minimal media containing 1\% GOS as a sole carbohydrate source were analyzed by HPLC to determine residual carbohydrates after incubation with each strain to early logarithm, late logarithm, and stationary growth phase. Three biological replicates, each in triplicate (three technical replications) were included in each experiment. The utilization of lactose and GOS varied between strains, and the production of lactic acid correlated with utilization.

\subsection{Gene Expression Analysis of L. rhamnosus in Medium Containing GOS as a Carbon Source}

In order to identify genes responding specifically to GOS, we compared the gene expression of L. rhamnosus strain cells harvested at mid-log phase $\left(\mathrm{OD}_{600 \mathrm{~nm}}=0.3-0.7\right)$ in MRS medium containing either $1 \%$ glucose, $1 \%$ GOS, or $0.1 \%$ lactose as sole carbohydrate sources (three biological replicates per treatment group). LGG was excluded from this analysis due to its inability to metabolize 
lactose and GOS. We identified 43 genes specifically overexpressed in response to GOS in AMC143, 16 genes in Lc705, and 21 genes in AMC010 when compared to expression levels in media containing glucose (Figure 4 and Supplementary Table S2). GOS treatment also resulted in underexpression of 31 genes in AMC143, five genes in Lc705, and 24 genes in AMC010 (Figure 4). The most overexpressed genes in AMC143 included the lac3 operon, an oligopeptide ABC transport (opp) operon, and L. rhamnosus-specific galactose operon (galKETRMa). Additionally, we identified three hypothetical and uncharacterized genes (FIG00754012, FIG00751425, and FIG00744856) conserved in L. rhamnosus, L. casei, and L. zeae, overexpressed by over 4-fold in AMC143 when exposed to GOS (Figures 4 and 5). When AMC010 was grown in GOS, overexpressed genes included the lac5 operon $\beta$-galactosidase genes, osm $C$, a pyruvate formate-lyase operon, galKETRMa operon, and $\alpha$-galactosidase genes. Interestingly, expression of the lac3 operon was reduced in AMC010 exposed to GOS. Like AMC143, lac3 was the most overexpressed operon when Lc705 was cultured in GOS-containing medium. Expression of an operon containing hypothetical cell surface proteins and a flagellar hook-length control gene (fliK) was reduced across all strains grown in GOS. Other genes differentially expressed in GOS are listed in Supplementary Table S2.

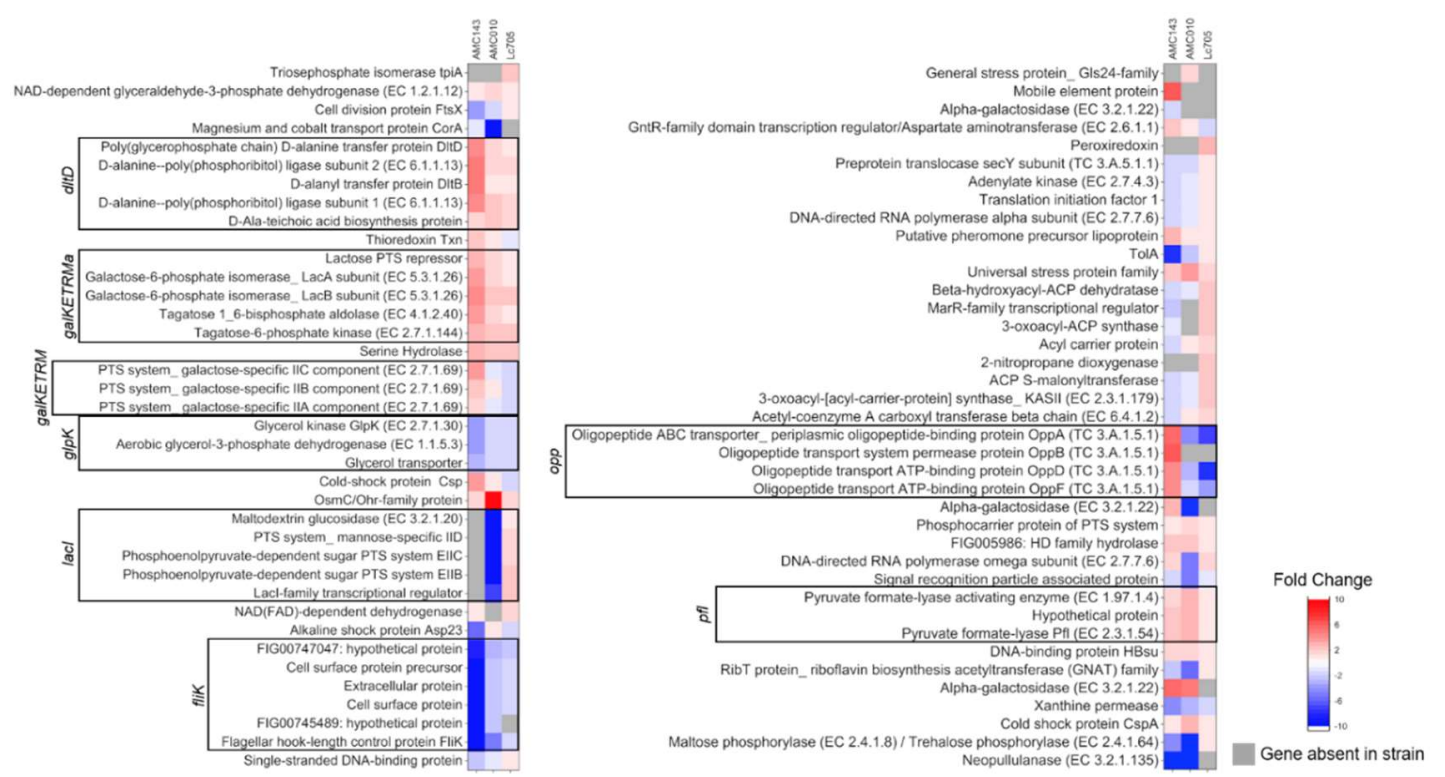

Figure 4. Transcriptomics analysis. Heat maps for AMC143, AMC010, and Lc705 were generated from sequencing reads mapped to their respective genome sequence and plotted to show fold changes between cultures in glucose compared to GOS. Boxed genes represent potential operons, and grayed genes represent genes absent in the associated strain. Three biological replicates were included in each experiment.

The lac3 operon was verexpressed 6-fold in AMC143 grown in GOS compared to glucose, but not in lactose (Figure 5). The same operon was overexpressed 3-fold in Lc705 grown in GOS but not in AMC010 cultured under either experimental condition. Operons lac1 and lac5 were both overexpressed in AMC010 grown in lactose or GOS, but were not differentially expressed in the other strains in this study. The lac2 operon was not differentially expressed in GOS or lactose in AMC010, but interestingly the homologous operon in AMC143 showed decreased expression in lactose-containing MRS (Figure 5). The highly conserved lac4 operon (Figure 1) was neither over- nor underexpressed in media with GOS or lactose in any of the strains. Lactose-specific PTS transporters in lac1, lac2, and lac3 operons were differentially regulated between strains exposed to GOS. Additionally, the expression of mannose-specific PTS transporters was down-regulated in AMC143 in GOS, but not in AMC010 under the same conditions. Galactose-specific PTS transporters were also up-regulated in AMC143 in GOS, but not in other strains. 


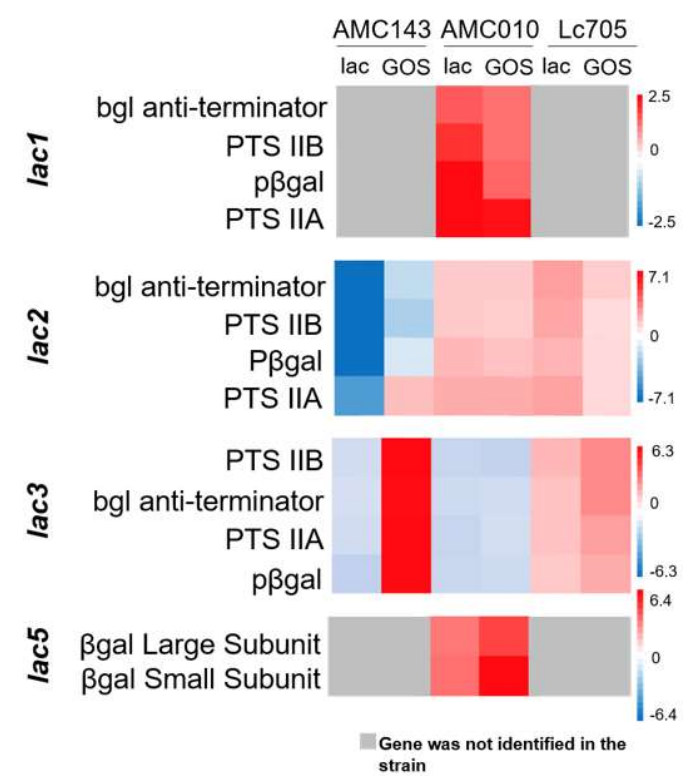

Figure 5. Expression of lac operons in GOS and lactose. Heat maps were generated from mRNA sequencing data for the identified lac operons in AMC143, AMC010, and Lc705, significantly differentially regulated by treatment with either GOS or lactose ( $p<0.05$ after Bonferroni correction). The fold change for each gene was determined by comparing expression data from lactose or GOS versus glucose. Gray boxes represent genes not identified in the corresponding genome. PTS: Phosphotransferase System.

With regards to transcriptional regulatory elements, the $\beta$-glucoside operon anti-terminator genes (bgl anti-terminator) present in operons lac1, lac2, and lac3 showed the same expression trends as their corresponding operons (Figure 5). Additionally, GOS resulted in up-regulated expression of the lactose PTS repressor in AMC143, in accordance with repression of the lac2 operon in this strain in GOS and lactose. In Lc705, a lacI family transcription repressor (LC705_RS01985), homologous to the LacI family DNA-binding transcriptional regulators in L. casei and L. paracasei (identified by BLASTx, Bethesda, MD, USA), was overexpressed in GOS and lactose but down-regulated in AMC010 grown under both conditions. This gene was absent in the genome of AMC143. Finally, exposure to GOS resulted in overexpression of an aspartate aminotransferase transcription regulator $(G n t R)$ and underexpression of a marR-family transcription regulator in AMC143. The marR gene was not differentially expressed in AMC010, but was over expressed by GOS in Lc705. Both genes were present in all L. rhamnosus strains, and highly conserved across L. rhamnosus, L. casei, and L. paracasei.

\subsection{Functional Characterization of lac3, A GOS-Specific Operon of L. rhamnosus AMC143}

The 6-phospho- $\beta$-galactosidase ( $p$ - $\beta$ gal_lac3) gene from the AMC143_lac3 operon was highly up-regulated in the presence of GOS, but not lactose. This operon was also overexpressed in Lc705, although to a lesser extent. To characterize the role of the 6-phospho- $\beta$-galactosidase gene and the lac3 in GOS metabolism, we inactivated the $p$ - $\beta g a l$ gene by disrupting the coding region through site-directed insertional inactivation in AMC143, generating the AMC143::p-pgal_lac3 strain. Inactivation of the $p$ - $\beta g a l \_l a c 3$ gene was confirmed by amplification and sequencing of the flanking regions in the section where the plasmid containing the gene fragment was inserted in the genome of AMC143 (not shown). The mutant strain was unable to grow in MRS broth containing either lactose or GOS as carbohydrate sources (Figure 6A). When grown in 1\% cellobiose, both wild type and mutant strains grew at the same rate, confirming that the inactivated gene functions as a $\beta$-galactosidase and

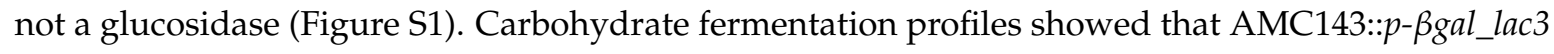
was unable to utilize pure GOS and was deficient in its ability to ferment D-lactose at $24 \mathrm{~h}$ (Figure 6B). This data conflicted with transcriptomic profiles, which showed that $p$ - $\beta g a l \_l a c 3$ was not induced in 
AMC143 by exposure to lactose (Figure 5), suggesting a different mechanism for the internalization of lactose, despite the role of p- $\beta$ gal_lac3 as the primary hydrolase for lactose fermentation.

A.


B.

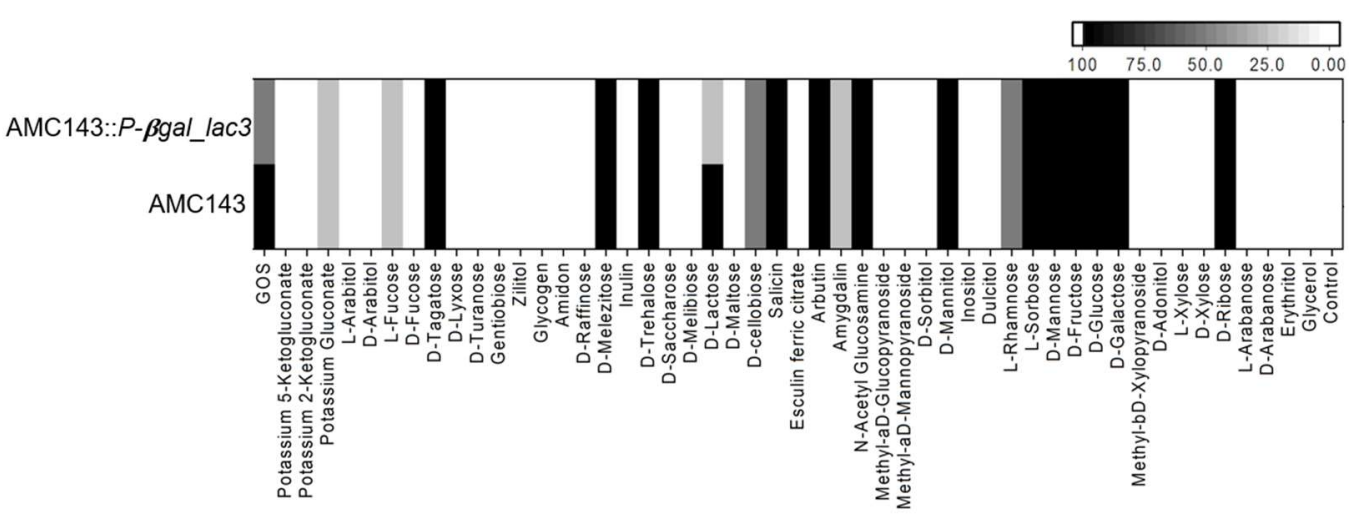

Figure 6. Growth and fermentation profiles of AMC143::p pgal_lac3. (A) Maximum specific growth rates for AMC143 and AMC143::_kgal_lac3 were determined in MRS containing 1\% glucose, 1\% GOS, $0.1 \%$ lactose, $1 \%$ cellobiose, and $0 \%$ glucose. Letters represent statistical differences between strain culture in each media type $(n=8, p<0.05)$. (B) Carbohydrate utilization profiles were generated by API $50 \mathrm{CH}$, revealing that the mutant was unable to ferment GOS and lactose after $24 \mathrm{~h}$.

\section{Discussion}

Pure galacto-oligosaccharides (GOS) have shown efficacy in alleviating symptoms associated with lactose intolerance [3,4]. However, variability in response to GOS has been reported [3,6]. Our previous work showed that the relative abundance of Bifidobacterium was inversely correlated with symptoms of pain and cramping in a Phase I clinical trial that evaluated pure GOS in lactose intolerant individuals [3], establishing a correlation between a measurable change in the gut microbiota, the 'bifidogenic response' (defined as an increase in abundance of this genus upon GOS consumption), and decreased lactose intolerance symptoms. These observations led us to hypothesize that the baseline composition of the gut microbiota at the strain level could contribute to response variability. We predicted that genomic and phenotypic differences at the strain level could impact GOS metabolism. In this study, we carried out an exhaustive characterization of the genetic systems involved in GOS metabolization in three strains of L. rhamnosus of intestinal origin, compared to a strain of dairy origin. The strains included in our analysis were a recognized human-derived probiotic strain (L. rhamnosus GG) [40], two strains previously isolated from infant stools (AMC143 and AMC010 [38,39]), and Lc705, of dairy origin [41]. We first performed comparative genomic analyses to identify operons encoding $\beta$-galactosidases and carbohydrate transport systems, finding that despite an overall identity between strains of over $95 \%$, there were unique genetic components in each strain. Upon identifying these differences, we performed physiological assays to characterize the ability of each strain to utilize GOS and other carbohydrate sources, revealing significant variability between strains. Transcriptomic analyses, performed to identify genes that were differentially regulated in each strain when using 
GOS as a sole carbohydrate source, provided insight into the lac3 operon in AMC143, which was subsequently disrupted and identified as a critical component of GOS fermentation.

Genomic analyses of the strains used in this study revealed both unique (lac1) and highly conserved (lac2, lac3) PTS operons containing 6-phospho- $\beta$-galactosidase genes or other $\beta$-galactosidases (lac4, lac5). The operons present in all strains shared a high degree of nucleotide identity (96.4-100\%). Similar operons containing 6-phospho- $\beta$-galactosidase genes have been described in other Lactobacillus species, including L. gasseri, L. acidophilus, and L. casei [51-53]. One of these hydrolases has been associated with the ability of L. casei strain BL23 to utilize oligosaccharides in human breast milk [54], similar to what we observed with AMC143_p Bgal_lac3. Likewise, multiple 6-phospho- $\beta$-galactosidase enzymes have been described in L. gasseri strain JCM1031, $p$ - $\beta g a l 1$ and $p$ - $\beta$ gal 2 , each with unique metabolic capabilities and kinetics $(116 \mu \mathrm{mol} / \mathrm{mg} / \mathrm{min}$ and $86 \mu \mathrm{mol} / \mathrm{mg} / \mathrm{min}$, respectively) [55,56], suggesting that differential expression of hydrolase genes may play a role in bacterial physiology related to the utilization of carbohydrates. This finding corroborated earlier studies that identified multiple $p$ - $\beta$ gal genes in L. gasseri strain NCK334 [57].

Phosphotransferase systems (PTS) have been extensively characterized in Lactobacillus [54,58], including L. rhamnosus as a mechanism for the transport of tagatose [44] and other carbohydrates into the cytoplasm [59]. Although L. casei, a close relative to L. rhamnosus, was among the first species of Lactobacillus shown to utilize PTS transporters to incorporate GOS tri- and tetrasaccharides [54], GOS transport via PTS has not been reported in L. rhamnosus. The primary mechanism for GOS transport in other lactobacilli involves permeases, such as LacS in L. acidophilus [37] and RafP in L. plantarum [60], which are absent in the L. rhamnosus strains in this study. Our study showed GOS-specific overexpression of the PTS components IIA and IIB in the lac3 operon in AMC 143 (BT102_01370, 01380); however, transport experiments will be essential to determine if these are involved in the incorporation of the oligosaccharides into the cell. Moreover, PTS transporters are highly specific for their substrates, but are often able to facilitate the transport of similar molecules [61]. As such, it stands to reason that lactose-specific PTS transporters may be capable of transporting larger GOS molecules into the cytoplasm due to their chemical similarity to lactose.

Our study showed that carbohydrate preferences varied between strains, and that this variability was a result of differential genetic capabilities and gene expression. No previous studies have shown the order of preference in which different oligosaccharides (di, tri, tetra or penta-saccharides) are consumed by different organisms, probably due to the lack of pure standard molecules for chromatography analysis,. Lc705, a strain of dairy origin, preferentially utilized lactose over trisaccharides, only metabolizing trisaccharides when lactose was not present, despite overexpression of the lac3 operon in this strain when grown in GOS. This operon was found to be critical for GOS utilization by AMC143. Similarly, operon lac2 was induced in both AMC010 and Lc705 by both lactose and GOS, but down-regulated in AMC143 under both conditions, suggesting a preferential mechanism for lactose utilization in these strains. Additionally, our data showed strains preferentially metabolized tri- over tetrasaccharides and longer oligosaccharides. We speculate that preference for trisaccharides is related with kinetics of GOS internalization, which has been shown to be important for the internalization of other carbohydrates [59,62].

Mobile genetic elements, including plasmids, allow for gene transfer and rapid evolution of bacterial populations $[63,64]$. Plasmids encoding enzymes relevant for carbohydrate metabolism have been described in Lactobacillus [52,65], suggesting that this group may have evolved to tolerate nutrient-limiting environments by carrying plasmids that extended their metabolic capabilities. Lc705 hosts plasmid FM179324.1 [41], which encodes a $\beta$-galactosidase gene $99.6 \%$ identical to the $\beta$-galactosidase gene in the AMC010 lac5 operon. This plasmid-encoded $\beta$-galactosidase was not overexpressed in Lc705 grown in GOS or lactose compared to glucose, but had a higher expression level in AMC010 when exposed to either of those components in the media. This plasmid is absent in AMC143 and LGG (strains that grow less effectively in pure lactose), suggesting that the ability 
of Lc705 and AMC010 to utilize lactose may have evolved through horizontal gene transfer of this carbohydrate utilization pathway, a phenomenon previously described in L. rhamnosus [63].

Physiological assays and mRNA sequencing revealed that the utilization of GOS and lactose by AMC143 is controlled by a highly conserved "lactose-specific PTS system" (lac3 operon), also present in AMC010 and Lc705, but absent in LGG. The inability of LGG to utilize either lactose or GOS is likely a consequence of these 6-phospho- $\beta$-galactosidase and PTS transporter genes being absent from its genome. However, even the strains that do utilize both lactose and GOS do so in different ways. For example, Lc705 and AMC010 preferentially utilize lactose. Lc705 will only begin to metabolize GOS trisaccharides after lactose in its growth media has been fully expended, while AMC010 does not break down GOS trisaccharides well, even in the absence of lactose. AMC143, however, is able to utilize GOS trisaccharides, even while lactose is still present. These observations, combined with mRNA sequencing results, suggest that different systems for GOS fermentation are utilized in a strain-specific manner. Insertional inactivation of the p- $\beta$ gal_lac3 gene in AMC143 confirmed the role of this operon in GOS utilization. Marginal utilization of the prebiotic by the mutant strain suggested a secondary mechanism present for the metabolism of internalized GOS. We propose that either the PTS transporter genes in the lac3 operon, or alternative transporters, still mediate GOS uptake in the mutant strain, where alternative, less-efficient enzymes metabolize the prebiotic, suggesting multiple mechanisms of utilization. This was reported in Corynebacterium, where carbohydrate transport occurs through both ABC and PTS transporters, allowing for more efficient transport than either system alone can provide [66]. Similar synergistic interactions between carbohydrate transport systems have not been described in Lactobacillus.

Gene expression varied between cells exposed to GOS and cells exposed to lactose compared to glucose, suggesting unique mechanisms for the utilization of each carbohydrate. In AMC143, inactivation of $p \beta g a l \_l a c 3$ inhibited growth in lactose as well as in GOS, although growth in a medium with lactose did not result in overexpression of the lac3 operon compared to glucose. Similarly, disruption of $A M C 143 \_p \beta g a l \_l a c 3$ did not affect growth rate in cellobiose, indicating that $p \beta g a l \_l a c 3$ is indeed a $\beta$-galactosidase rather than a glucosidase. RNA sequencing showed overexpression of an operon containing cellobiose-specific PTS transporters and a 6-phospho- $\beta$-glucosidase gene in AMC143 (BT102_10960-10980) when exposed to lactose. This suggests that the cellobiose-specific PTS transporter in AMC143 may facilitate the transport of lactose, while a different system in AMC143 is used for the transport of GOS. Despite utilizing different transport systems, the same galactosidase ( $p$ Bgal_lac3) is used to metabolize both carbohydrates.

Our data on strain-level variability strengthen the argument for exhaustive physiological characterization of individual probiotics, especially in the context of synbiotic development. A recent study showed that probiotic Bifidobacterium strains given to obese adult individuals along with GOS improved intestinal physiology, without synergistic effects. Both treatments improved colon permeability, however synergistic benefits were not shown in patients treated with both the probiotic Bifidobacterium and GOS together [67]. Since different bacterial strains can have different capabilities to utilize prebiotics, without an in-depth characterization of individual strains it is challenging to determine whether or not the lack of synergy in a synbiotic mixture is due to inability of the probiotic bacteria to ferment the prebiotic substrate. Likewise, it is important to note that bacterial physiology within a complex community most probably will not mirror responses from an in vitro system, as undefined or uncharacterized microorganisms will also contribute to GOS metabolism. Further studies, including validation experiments in complex gut-mimicking bioreactors, will be useful to determine if the strains perform in a similar manner within a complex gut ecosystem.

Our study highlights the importance of combining classical microbiology approaches with high-throughput sequencing techniques when studying microorganisms of probiotic potential. Whole Genome Shotgun (WGS) sequencing is widely used to identify prevalent genes and extrapolate function from data $[68,69]$; however, research demonstrates that, while the presence of a gene may 
provide a basis for a hypothesis regarding function, physiological and expression data are required to determine functionality.

Supplementary Materials: The following materials are available online at http:/ / www.mdpi.com/2072-6643/ 10/10/1517/s1. Figure S1: Growth of AMC143 and AMC143::p pgal_lac3 in lactose and cellobiose. Growth curves were calculated for wild type and mutant AMC143 strains by measuring the optical density at $600 \mathrm{~nm}\left(\mathrm{OD}_{600 \mathrm{~nm}}\right)$ every $15 \mathrm{~min}$ over a $24 \mathrm{~h}$ period in MRS media containing either $1 \%$ lactose or $1 \%$ cellobiose as a sole carbohydrate source $(n=8)$, Table S1: Carbohydrate utilization profiles of L. rhamnosus. The ability of AMC143, AMC010, Lc705 and LGG to ferment different carbohydrates was assessed using the API 50CH test kit. Two biological replicates were included in each test. The degree of utilization for each substrate is presented in the table, Table S2: Differential gene expression in GOS and lactose. Expression data from AMC143, AMC010, and Lc705 cultures in $1 \%$ GOS or $0.1 \%$ lactose (vehicle control), each run in triplicate, compared to glucose. The $p$-value was calculated by binomial distribution analysis in Geneious software with Bonferroni correction for multiple comparisons.

Author Contributions: J.W.A.: Formal analysis, methodology, validation, writing-original draft; J.B.S.: Investigation, methodology; J.R.: Formal analysis, software; writing-review \& editing; J.M.B.-B.: Conceptualization, methodology, writing - review \& editing; M.A.A.-P.: Conceptualization, funding acquisition, project administration, supervision, writing - review \& editing.

Funding: The UNC Microbiome Core is supported in part by NIH grant P30 DK34987.

Acknowledgments: The authors wish to express their gratitude to Jakub Kwintkiewicz for his technical advice.

Conflicts of Interest: No conflict of interest.

\section{References}

1. Deng, Y.; Misselwitz, B.; Dai, N.; Fox, M. Lactose intolerance in adults: Biological mechanism and dietary management. Nutrients 2015, 7, 8020-8035. [CrossRef] [PubMed]

2. Oak, S.J.; Jha, R. The effects of probiotics in lactose intolerance: A systematic review. Crit. Rev. Food Sci. Nutr. 2018, 1-9. [CrossRef] [PubMed]

3. Azcarate-Peril, M.A.; Ritter, A.J.; Savaiano, D.; Monteagudo-Mera, A.; Anderson, C.; Magness, S.T.; Klaenhammer, T.R. Impact of short-chain galactooligosaccharides on the gut microbiome of lactose-intolerant individuals. Proc. Natl. Acad. Sci. USA 2017, 114, E367-E375. [CrossRef] [PubMed]

4. Savaiano, D.A.; Ritter, A.J.; Klaenhammer, T.R.; James, G.M.; Longcore, A.T.; Chandler, J.R.; Walker, W.A.; Foyt, H.L. Improving lactose digestion and symptoms of lactose intolerance with a novel galacto-oligosaccharide (RP-G28): A randomized, double-blind clinical trial. Nutr. J. 2013, 12, 160. [CrossRef] [PubMed]

5. Azcarate Peril, M.A.; Savaiano, D.A.; Ritter, A.J.; Klaenhammer, T. Microbiome alterations of lactose intolerant individuals in response to dietary intervention with galacto-oligosaccharides may help negate symptoms of lactose intolerance. Gastroenterology 2013, 144, S-893. [CrossRef]

6. Davis, L.M.; Martinez, I.; Walter, J.; Goin, C.; Hutkins, R.W. Barcoded pyrosequencing reveals that consumption of galactooligosaccharides results in a highly specific bifidogenic response in humans. PLOS ONE 2011, 6, e25200. [CrossRef] [PubMed]

7. Torres, D.P.M.; Gonçalves, M.D.P.F.; Teixeira, J.A.; Rodrigues, L.R. Galacto-oligosaccharides: Production, properties, applications, and significance as prebiotics. Compr. Rev. Food Sci. Food Saf. 2010, 9, 438-454. [CrossRef]

8. Chey, W.D.; Sandborn, W.J.; Ritter, A.J.; Foyt, H.; Azcarate-Peril, M.A.; Savaiano, D.A. Multiple clinical outcomes improve in lactose intolerance patients after treatment with novel galacto-oligosaccharide, RP-G28. Unpublished work, 2018.

9. Cardelle-Cobas, A.; Corzo, N.; Olano, A.; Pelaez, C.; Requena, T.; Avila, M. Galactooligosaccharides derived from lactose and lactulose: Influence of structure on Lactobacillus, Streptococcus and Bifidobacterium growth. Int. J. Food Microbiol. 2011, 149, 81-87. [CrossRef] [PubMed]

10. Francavilla, R.; Calasso, M.; Calace, L.; Siragusa, S.; Ndagijimana, M.; Vernocchi, P.; Brunetti, L.; Mancino, G.; Tedeschi, G.; Guerzoni, E.; et al. Effect of lactose on gut microbiota and metabolome of infants with cow's milk allergy. Pediatr. Allergy Immunol. Off. Publ. Eur. Soc. Pediatr. Allergy Immunol. 2012, 23, 420-427. [CrossRef] [PubMed]

11. Hobbs, M.E.; Williams, H.J.; Hillerich, B.; Almo, S.C.; Raushel, F.M. L-galactose metabolism in Bacteroides vulgatus from the human gut microbiota. Biochemistry 2014, 53, 4661-4670. [CrossRef] [PubMed] 
12. Do, M.H.; Lee, E.; Oh, M.J.; Kim, Y.; Park, H.Y. High-glucose or -fructose diet cause changes of the gut microbiota and metabolic disorders in mice without body weight change. Nutrients 2018, 10, 761. [CrossRef] [PubMed]

13. Lebeer, S.; Claes, I.; Tytgat, H.L.; Verhoeven, T.L.; Marien, E.; von Ossowski, I.; Reunanen, J.; Palva, A.; Vos, W.M.; Keersmaecker, S.C.; et al. Functional analysis of Lactobacillus rhamnosus GG pili in relation to adhesion and immunomodulatory interactions with intestinal epithelial cells. Appl. Environ. Microbiol. 2012, 78, 185-193. [CrossRef] [PubMed]

14. Medina, M.; Izquierdo, E.; Ennahar, S.; Sanz, Y. Differential immunomodulatory properties of Bifidobacterium longum strains: Relevance to probiotic selection and clinical applications. Clin. Exp. Immunol. 2007, 150, 531-538. [CrossRef] [PubMed]

15. Pham, T.A.N.; Lawley, T.D. Emerging insights on intestinal dysbiosis during bacterial infections. Curr. Opin. Microbiol. 2014, 17, 67-74. [CrossRef] [PubMed]

16. Hudault, S.; Lievin, V.; Bernet-Camard, M.F.; Servin, A.L. Antagonistic activity exerted in vitro and in vivo by Lactobacillus casei (strain GG) against Salmonella typhimurium c5 infection. Appl. Environ. Microbiol. 1997, 63, 513-518. [PubMed]

17. Tang, J. Microbial metabolomics. Curr. Genom. 2011, 12, 391-403. [CrossRef] [PubMed]

18. Ursell, L.K.; Haiser, H.J.; Van Treuren, W.; Garg, N.; Reddivari, L.; Vanamala, J.; Dorrestein, P.C.; Turnbaugh, P.J.; Knight, R. The intestinal metabolome: An intersection between microbiota and host. Gastroenterology 2014, 146, 1470-1476. [CrossRef] [PubMed]

19. Ferguson, L.R. Nutritional modulation of gene expression: Might this be of benefit to individuals with crohn's disease? Front. Immunol. 2015, 6, 467. [CrossRef] [PubMed]

20. Walsh, C.J.; Guinane, C.M.; O'Toole, P.W.; Cotter, P.D. Beneficial modulation of the gut microbiota. FEBS Lett. 2014, 588, 4120-4130. [CrossRef] [PubMed]

21. Islam, S.U. Clinical uses of probiotics. Medicine 2016, 95, e2658. [CrossRef] [PubMed]

22. Reid, G.; Jass, J.; Sebulsky, M.T.; McCormick, J.K. Potential uses of probiotics in clinical practice. Clin. Microbiol. Rev. 2003, 16, 658-672. [CrossRef] [PubMed]

23. Corzo, N.; Alonso, J.L.; Azpiroz, F.; Calvo, M.A.; Cirici, M.; Leis, R.; Lombo, F.; Mateos-Aparicio, I.; Plou, F.J.; Ruas-Madiedo, P.; et al. Prebiotics: Concept, properties and beneficial effects. Nutr. Hosp. 2015, 31 (Suppl. 1), 99-118. [PubMed]

24. Reid, G.; Sanders, M.E.; Gaskins, H.R.; Gibson, G.R.; Mercenier, A.; Rastall, R.; Roberfroid, M.; Rowland, I.; Cherbut, C.; Klaenhammer, T.R. New scientific paradigms for probiotics and prebiotics. J. Clin. Gastroenterol. 2003, 37, 105-118. [CrossRef] [PubMed]

25. Tannock, G.W.; Taylor, C.; Lawley, B.; Loach, D.; Gould, M.; Dunn, A.C.; McLellan, A.D.; Black, M.A.; McNoe, L.; Dekker, J.; et al. Altered transcription of murine genes induced in the small bowel by administration of probiotic strain Lactobacillus rhamnosus HN001. Appl. Environ. Microbiol. 2014, 80, 2851-2859. [CrossRef] [PubMed]

26. Chapman, C.M.; Gibson, G.R.; Rowland, I. In vitro evaluation of single- and multi-strain probiotics: Inter-species inhibition between probiotic strains, and inhibition of pathogens. Anaerobe 2012, 18, 405-413. [CrossRef] [PubMed]

27. Hutt, P.; Shchepetova, J.; Loivukene, K.; Kullisaar, T.; Mikelsaar, M. Antagonistic activity of probiotic lactobacilli and bifidobacteria against entero- and uropathogens. J. Appl. Microbiol. 2006, 100, 1324-1332. [CrossRef] [PubMed]

28. De Vrese, M.; Schrezenmeir, J. Probiotics, prebiotics, and synbiotics. Adv. Biochem. Eng. Biotechnol. 2008, 111, 1-66. [PubMed]

29. Lebeer, S.; Vanderleyden, J.; De Keersmaecker, S.C. Genes and molecules of lactobacilli supporting probiotic action. Microbiol. Mol. Boil. Rev. 2008, 72, 728-764. [CrossRef] [PubMed]

30. Papadimitriou, K.; Zoumpopoulou, G.; Foligné, B.; Alexandraki, V.; Kazou, M.; Pot, B.; Tsakalidou, E. Discovering probiotic microorganisms: In vitro, in vivo, genetic and omics approaches. Front. Microbiol. 2015, 6. [CrossRef] [PubMed]

31. Andriantsoanirina, V.; Allano, S.; Butel, M.J.; Aires, J. Tolerance of Bifidobacterium human isolates to bile, acid and oxygen. Anaerobe 2013, 21, 39-42. [CrossRef] [PubMed] 
32. Papadimitriou, K.; Alegria, A.; Bron, P.A.; de Angelis, M.; Gobbetti, M.; Kleerebezem, M.; Lemos, J.A.; Linares, D.M.; Ross, P.; Stanton, C.; et al. Stress physiology of lactic acid bacteria. Microbiol. Mol. Biol. Rev. 2016, 80, 837-890. [CrossRef] [PubMed]

33. Arnold, J.W.; Simpson, J.B.; Roach, J.; Kwintkiewicz, J.; Azcarate-Peril, M.A. Intra-species genomic and physiological variability impact stress resistance in strains of probiotic potential. Front. Microbiol. 2018, 9, 242. [CrossRef] [PubMed]

34. Markowiak, P.; Śliżewska, K. Effects of probiotics, prebiotics, and synbiotics on human health. Nutrients 2017, 9, 2021.

35. Zhang, C.; Zhao, L. Strain-level dissection of the contribution of the gut microbiome to human metabolic disease. Genome Med. 2016, 8, 41. [CrossRef] [PubMed]

36. Greenblum, S.; Carr, R.; Borenstein, E. Extensive strain-level copy-number variation across human gut microbiome species. Cell 2015, 160, 583-594. [CrossRef] [PubMed]

37. Andersen, J.M.; Barrangou, R.; Abou Hachem, M.; Lahtinen, S.; Goh, Y.J.; Svensson, B.; Klaenhammer, T.R. Transcriptional and functional analysis of galactooligosaccharide uptake by lacS in Lactobacillus acidophilus. Proc. Natl. Acad. Sci. USA 2011, 108, 17785-17790. [CrossRef] [PubMed]

38. Arnold, J.W.; Monteagudo-Mera, A.; Altermann, E.; Cadenas, M.B.; Thompson, A.L.; Azcarate-Peril, M.A. Genome sequences of potential probiotic isolates from human infants. Genome Announc. 2017, 5. [CrossRef]

39. Thompson, A.L.; Monteagudo-Mera, A.; Cadenas, M.B.; Lampl, M.L.; Azcarate-Peril, M. Milk-and solid-feeding practices and daycare attendance are associated with differences in bacterial diversity, predominant communities, and metabolic and immune function of the infant gut microbiome. Front. Cell. Infect. Microbiol. 2015, 5. [CrossRef] [PubMed]

40. Silva, M.; Jacobus, N.V.; Deneke, C.; Gorbach, S.L. Antimicrobial substance from a human Lactobacillus strain. Antimicrob. Agents Chemother. 1987, 31, 1231-1233. [CrossRef] [PubMed]

41. Kankainen, M.; Paulin, L.; Tynkkynen, S.; von Ossowski, I.; Reunanen, J.; Partanen, P.; Satokari, R.; Vesterlund, S.; Hendrickx, A.P.; Lebeer, S.; et al. Comparative genomic analysis of Lactobacillus rhamnosus GG reveals pili containing a human- mucus binding protein. Proc. Natl. Acad. Sci. USA 2009, 106, 17193-17198. [CrossRef] [PubMed]

42. Bruno-Barcena, J.M.; Azcarate-Peril, M.A. Galacto-oligosaccharides and colorectal cancer: Feeding our intestinal probiome. J. Funct. Foods 2015, 12, 92-108. [CrossRef] [PubMed]

43. Dagher, S.F.; Azcarate-Peril, M.A.; Bruno-Barcena, J.M. Heterologous expression of a bioactive $\beta$-hexosyltransferase, an enzyme producer of prebiotics, from Sporobolomyces singularis. Appl. Environ. Microbiol. 2013, 79, 1241-1249. [CrossRef] [PubMed]

44. Welker, D.L.; Hughes, J.E.; Steele, J.L.; Broadbent, J.R. High efficiency electrotransformation of Lactobacillus casei. FEMS Microbiol. Lett. 2015, 362, 1-6. [CrossRef] [PubMed]

45. Kim, Y.H.; Han, K.S.; Oh, S.; You, S.; Kim, S.H. Optimization of technical conditions for the transformation of lactobacillus acidophilus strains by electroporation. J. Appl. Microbiol. 2005, 99, 167-174. [CrossRef] [PubMed]

46. Thongaram, T.; Hoeflinger, J.L.; Chow, J.; Miller, M.J. Prebiotic galactooligosaccharide metabolism by probiotic lactobacilli and bifidobacteria. J. Agric. Food Chem. 2017, 65, 4184-4192. [CrossRef] [PubMed]

47. Kumari, M.; Swarnkar, M.K.; Kumar, S.; Singh, A.K.; Gupta, M. Complete genome sequence of potential probiotic Lactobacillus sp. Hfc8, isolated from human gut using PacBio SMRT sequencing. Genome Announc. 2015, 3. [CrossRef] [PubMed]

48. Solovyev, V.; Salamov, A. Automatic annotation of microbial genomes and metagenomic sequences in metagenomics and its applications in agriculture. Biomed. Environ. Stud. 2011, 18, 61-78.

49. Gautheret, D.; Lambert, A. Direct RNA motif definition and identification from multiple sequence alignments using secondary structure profiles. J. Mol. Biol. 2001, 313, 1003-1011. [CrossRef] [PubMed]

50. Bettenbrock, K.; Siebers, U.; Ehrenreich, P.; Alpert, C.A. Lactobacillus casei 64 h contains a phosphoenolpyruvate-dependent phosphotransferase system for uptake of galactose, as confirmed by analysis of ptsh and different gal mutants. J. Bacteriol. 1999, 181, 225-230. [PubMed]

51. Honda, H.; Nagaoka, S.; Kawai, Y.; Kemperman, R.; Kok, J.; Yamazaki, Y.; Tateno, Y.; Kitazawa, H.; Saito, T. Purification and characterization of two phospho- $\beta$-galactosidases, lacg1 and lacg2, from Lactobacillus gasseri ATCC33323(t). J. Gen. Appl. Microbiol. 2012, 58, 11-17. [CrossRef] [PubMed] 
52. Takala, T.M.; Saris, P.E.; Tynkkynen, S.S. Food-grade host/vector expression system for Lactobacillus casei based on complementation of plasmid-associated phospho- $\beta$-galactosidase gene lacg. Appl. Microbiol. Biotechnol. 2003, 60, 564-570. [CrossRef] [PubMed]

53. Saito, T.; Suzuki, M.; Konno, K.; Kitazawa, H.; Kawai, Y.; Itoh, T.; Kamio, Y. Molecular cloning and sequencing of two phospho- $\beta$-galactosidase I and II genes of Lactobacillus gasseri JCM1031 isolated from human intestine. Biosci. Biotechnol. Biochem. 1998, 62, 2318-2327. [CrossRef] [PubMed]

54. Bidart, G.N.; Rodriguez-Diaz, J. The lactose operon from Lactobacillus casei is involved in the transport and metabolism of the human milk oligosaccharide core-2 n-acetyllactosamine. Sci. Rep. 2018, 8, 7152. [CrossRef] [PubMed]

55. Suzuki, M.; Saito, T.; Itoh, T. Coexistence of two kinds of 6-phospho- $\beta$-galactosidase in the cytosol of Lactobacillus gasseri JCM1031-purification and characterization of 6-phospho- $\beta$-galactosidase II. Biosci. Biotechnol. Biochem. 1996, 60, 708-710. [CrossRef] [PubMed]

56. Suzuki, M.; Saito, T.; Itoh, T. Purification and characterization of 6-phospho- $\beta$-galactosidase from Lactobacillus gasseri JCM1031. Biosci. Biotechnol. Biochem. 1996, 60, 139-141. [CrossRef] [PubMed]

57. Bruno-Barcena, J.M.; Azcarate-Peril, M.A.; Klaenhammer, T.R.; Hassan, H.M. Marker-free chromosomal integration of the manganese superoxide dismutase gene (soda) from streptococcus thermophilus into Lactobacillus gasseri. FEMS Microbiol. Lett. 2005, 246, 91-101. [CrossRef] [PubMed]

58. Koh, J.H.; Choi, S.H.; Park, S.W.; Choi, N.J.; Kim, Y.; Kim, S.H. Synbiotic impact of tagatose on viability of Lactobacillus rhamnosus strain GG mediated by the phosphotransferase system (PTS). Food Microbiol. 2013, 36, 7-13. [CrossRef] [PubMed]

59. Ganzle, M.G.; Follador, R. Metabolism of oligosaccharides and starch in lactobacilli: A review. Front. Microbiol. 2012, 3, 340. [CrossRef] [PubMed]

60. Silvestroni, A.; Connes, C.; Sesma, F.; De Giori, G.S.; Piard, J.C. Characterization of the mela locus for $\alpha$-galactosidase in Lactobacillus plantarum. Appl. Environ. Microbiol. 2002, 68, 5464-5471. [CrossRef] [PubMed]

61. Miller, K.A.; Phillips, R.S.; Kilgore, P.B.; Smith, G.L.; Hoover, T.R. A mannose family phosphotransferase system permease and associated enzymes are required for utilization of fructoselysine and glucoselysine in Salmonella enterica serovar typhimurium. J. Bacteriol. 2015, 197, 2831-2839. [CrossRef] [PubMed]

62. Vallino, J.J.; Hopkinson, C.S.; Hobbie, J.E. Modeling bacterial utilization of dissolved organic matter: Optimization replaces monod growth kinetics. Limnol. Oceanogr. 1996, 41, 1591-1609. [CrossRef]

63. Ceapa, C.; Davids, M.; Ritari, J.; Lambert, J.; Wels, M.; Douillard, F.P.; Smokvina, T.; de Vos, W.M.; Knol, J.; Kleerebezem, M. The variable regions of Lactobacillus rhamnosus genomes reveal the dynamic evolution of metabolic and host-adaptation repertoires. Genome Boil. Evol. 2016, 8, 1889-1905. [CrossRef] [PubMed]

64. Bellanger, X.; Payot, S.; Leblond-Bourget, N.; Guedon, G. Conjugative and mobilizable genomic islands in bacteria: Evolution and diversity. FEMS Microbiol. Rev. 2014, 38, 720-760. [CrossRef] [PubMed]

65. Chassy, B.M.; Alpert, C.A. Molecular characterization of the plasmid-encoded lactose-pts of Lactobacillus casei. FEMS Microbiol. Rev. 1989, 5, 157-165. [CrossRef]

66. Henrich, A.; Kuhlmann, N.; Eck, A.W.; Kramer, R.; Seibold, G.M. Maltose uptake by the novel abc transport system musEFGK 2 I causes increased expression of ptsG in Corynebacterium glutamicum. J. Bacteriol. 2013, 195, 2573-2584. [CrossRef] [PubMed]

67. Krumbeck, J.A.; Rasmussen, H.E.; Hutkins, R.W.; Clarke, J.; Shawron, K.; Keshavarzian, A.; Walter, J. Probiotic Bifidobacterium strains and galactooligosaccharides improve intestinal barrier function in obese adults but show no synergism when used together as synbiotics. Microbiome 2018, 6, 121. [CrossRef] [PubMed]

68. Mitra, S.; Förster-Fromme, K.; Damms-Machado, A.; Scheurenbrand, T.; Biskup, S.; Huson, D.H.; Bischoff, S.C. Analysis of the intestinal microbiota using solid 16S rRNA gene sequencing and solid shotgun sequencing. BMC Genom. 2013, 14, S16. [CrossRef] [PubMed]

69. Kanehisa, M.; Goto, S.; Kawashima, S.; Okuno, Y.; Hattori, M. The KEGG resource for deciphering the genome. Nucleic Acids Res. 2004, 32, D277-D280. [CrossRef] [PubMed]

(C) 2018 by the authors. Licensee MDPI, Basel, Switzerland. This article is an open access article distributed under the terms and conditions of the Creative Commons Attribution (CC BY) license (http:// creativecommons.org/licenses/by/4.0/). 